\title{
GAME THEORY AND 2 x 2 STRATEGIC GAMES APPLIED FOR MODELING OIL AND GAS INDUSTRY DECISION-MAKING PROBLEMS
}

\author{
Felipe Costa Araujo* and Alexandre Bevilacqua Leoneti
}

Received November 28, 2017 / Accepted July 31, 2018

\begin{abstract}
Oil and gas resources have been considered valuable assets, associated with potential conflicts due to distinct interests of many agents involved in their exploration, such as producing and consuming countries, governments and companies. These conflicts can show up under many situations and market conditions, such as partnerships, joint development, optimal outputs and reserve maximization. Game theory is known as a methodology that improves the decision-making processes by better understanding the players' specific motivations, strategic interactions and payoff estimation. A widely used framework for modeling social and economic phenomena is the $2 \times 2$ strategic games, of which include classical forms such as Prisoner's Dilemma, Stag Hunt, and Battle of Sexes. Therefore, this paper proposes to examine relevant realistic and real-world cases of the oil and gas industry in the form of $2 \times 2$ strategic games, aiming to investigate game theory approaches to aid in the discussion and resolution of the main dilemmas faced.
\end{abstract}

Keywords: Game theory, 2 x 2 strategic games, oil and gas.

\section{INTRODUCTION}

Due to the wide range of possible conflicts, from small disagreements to international military campaigns, there is a great demand for formal methodologies to understand and evaluate realworld conflicts (Hipel et al., 2011). Arsenyan et al. (2015) commented that game theory is a well-known tool to model the potential conflicts among agents, providing insights on how to negotiate or collaborate under particular conditions, looking for equilibrium solutions. The main goal is to predict the consequences of making potential choices for all players involved in order to select the best possible action (Kelly, 2003). Souza \& Rego (2013) added that conflicting and cooperative strategic choices could have a huge influence on the agents' outcome in any strategic interaction. The main contributions of game theory approaches are to understand how agents interact strategically under some basic assumption of rationality, and taking into account the expectations of other agents in their choices (Osborne \& Rubinstein, 1994).

*Corresponding author.

Grupo de Pesquisa em Ciências da Decisão - Faculdade de Economia, Administração e Contabilidade de Ribeirão Preto (FEARP-USP), Av. Bandeirantes 3900, 14040-900 Ribeirão Preto, SP, Brasil.

-E-mails: fcaraujo@usp.br; ableoneti@usp.br 
The oil and gas industry is characterized as a dynamic business environment dominated by corporate partnerships and joint ventures, as well as tight governmental regulation, where the understanding of all these agents' interests is particularly important to solve potential conflicts (Willigers et al., 2009; Zhu \& Singh, 2016). Oliveira et al. (2016) mentioned that the oil and gas industry is characterized as a competitive environment with many current challenges, such as price fluctuation, environmental conservation, and partnership among major companies. This industry is also characterized by huge investment requirements, generally executed by partnerships and joint ventures for cost and risk sharing (Castillo \& Dorao, 2013). Seixas (2009) and Johnston (1994) argued that the main objectives of partnerships and joint ventures among oil and gas companies are to share risks, maximize investment portfolios and optimize short and long-term strategies. Consequently, the process of allocating capital into the correct portfolio is a critical factor for the oil and gas industry when evaluating possible partnerships (Lopes \& Almeida, 2013). Another source of potential conflicts among partnerships is the vertical integration between oil and gas exploration companies and their suppliers, with the goal to share their particular risks and costs (Hamacker \& Martins, 2015). Hence, the presence of multiple agents and the impact that each distinct strategy has over the final outcomes make the oil and gas industry an interesting field for game theory applications.

Bratvold \& Koch (2011) argued that potential game theory applications in the oil and gas industry can be grouped into three main categories: (i) competitive bidding, in which companies usually face strong competition among themselves in bids or auctions for oil and gas exploration opportunities; (ii) negotiation between partners, allowing the companies to look at the negotiation from all possible sides, discovering key trade-offs and accepting terms to create win-win solutions; and (iii) joint ventures and partnerships, in which oil and gas companies need to evaluate cooperation initiatives with their competitors, governments, investors and others, in order to understand their partners and develop strategies to achieve the best outcome. Willigers et al. (2009) added two other potential practical applications: (iv) rivalry between service providers, whereby service companies generally compete to be suppliers of oil and gas companies and should decide their strategies based on the relationship between profitability and risks of losing the bid; and (v) employee unions relationship, whereby although oil and gas employees and corporate management might have conflicting objectives, both parties should understand each other and cooperate to maintain business sustainability. Nakhle (2008) complemented saying that regional rivalries could be a potential source of many conflicts of interest which affect the oil and gas industry, such as: (i) the UK-Scotland tax rate division conflict; (ii) tribal conflicts in Western Sudan; (iii) division of oil and gas earnings in Russia; (iv) conflicts among some countries in the Caucasus region concerning oil and gas pipelines; and (v) intense regional rivalries in Iraq about the division of its oil and gas resources and revenues.

In this context, game-theoretic models can aid in the adequate visualization of the strategic interactions faced by the oil and gas industry, with the main goal of a better understanding of the issues or problems, aiming to improve the decision-making processes. By applying a game theory approach it is possible to identify an intrinsic and particular logical structure, where 
different frameworks for modeling them exclusively are needed. For social and economic interaction and interdependent decision-making processes, the framework of mixed-motive games, with the specific case of 2 × 2 symmetric games, are the most used (Kelly, 2003). Decanio \& Fremstad (2013) mentioned that the 2 x 2 symmetrical games were summarized by Robinson \& Goforth (2005), who proposed to organize and classify these games as a "New Periodic Table" (NPT) in a unified topological framework based on a natural measure of the players' payoff structures. According to Robinson \& Goforth (2005), Von Neumann and Morgenstern were the pioneers in providing the foundations of game theory methodologies. Rapoport \& Guyer (1978), Rapoport et al. (1976) and Brams (1994) proposed a more organized and structured game theory approach which produced typologies of 2 × 2 games. Nonetheless, Robinson \& Goforth (2005) argued that these typologies can be replaced by the topologies presented in the NPT because they provide an easier, more flexible and better relationship understanding, as well as an improved design for generating testable hypotheses about 2 × 2 strategic games.

The 2 x 2 strategic games represent a simplified situation with only two players and two possible symmetric options, aiming to capture the main strategically interaction necessary in order allow the analysis of more complex environments (Osborne \& Rubinstein, 1994). Fiani (2015) added that these simplified games could support the understanding and the analysis of similar and more complex real-world situations. The results of these games are presented as a payoff matrix, which represents the ordinal ranking of the outcomes identified for the strategic interaction (Decanio \& Fremstad, 2013). Hence, the payoff matrix is represented by four cells with two elements, the first number of the cell specifies the payoff value of the Row Player and the second number presents the payoff of the Column Player, as indicated in Table 1.

Table 1 - Payoff matrix notation for a generic $2 \times 2$ strategic game.

Source: Adapted from Robinson \& Goforth (2005) and Decanio \& Fremstad (2013).

\begin{tabular}{c|c|c}
\hline Row Player's & \multicolumn{2}{|c}{ Column Player's Strategies } \\
\cline { 2 - 3 } Strategies & Strategy A & Strategy B \\
\hline Strategy A & $\mathrm{a}, \mathrm{u}$ & $\mathrm{b}, \mathrm{v}$ \\
\hline Strategy B & $\mathrm{c}, \mathrm{w}$ & $\mathrm{d}, \mathrm{x}$ \\
\hline
\end{tabular}

The 2 x 2 strategic game classification proposed by Robinson \& Goforth (2005) was based on the players' payoff-space representation, especially in the understanding and interpretation of the solutions provided by the Nash equilibrium and Maxi-min strategy. The Nash equilibrium searches for the best possible strategic option when compared to other players' options, and this is true for all players (Nash, 1951). On the other hand, the Maxi-min strategy searches for payoffs that are at least as good as the worst payoff from any other strategy (Robinson \& Goforth, 2005). According to Robinson \& Goforth (2005), among the 144 ways of modeling 2 x 2 symmetric games, seven are most relevant, namely: (i) Prisoner's Dilemma, players have robust incentives to take a different strategy without taking into account other players, known as free-riding (Decanio 
\& Fremstad, 2013); (ii) Stag Hunt, also known as the Stag and Hare game, players agree to cooperate to hunt a stag, however during the hunt they can see a hare and change their initial agreement (Binmore, 2007); (iii) Chicken game, players have strong incentives to take distinct strategies from each other, however the equilibrium is only achieved when both parties find a way to work out their risk aversion and choose the same strategy (Decanio \& Fremstad, 2013); (iv) two versions of Battle of Sexes, the best outcomes are only achieved when players take coordinated decisions, even with their distinct preferences about the action to be taken (Luce \& Raiffa, 1957); and (v) two Coordination games, social interaction situations in which no player would be better off whether any other player unilaterally made a different choice (Robinson \& Goforth, 2005).

The main scope of this paper is to discuss the application of these most common $2 \times 2$ strategic games for modeling realistic examples and real-world situations of the oil and gas industry. The goal is to provide an adequate visualization of the strategic interactions of several situations, such as auctions, partnerships, cooperation strategies, reservoir optimization, and relationships among countries. These strategic interactions can potentially affect the decision-making processes of the agents involved in the oil and gas industry, such as oil producing and consuming countries, governments, and companies. Therefore, the main contributions of this paper are to provide fresh insights by using a game theory approach, aiming to improve the understanding of the players' interests and to deeply analyze their motivations, numerically expressed by their payoff structures. The paper is organized as follows: (i) Section 2 details the methodological procedure used to select the papers of game theory applications in the oil and gas industry; (ii) Section 3 presents and details these applications divided into Prisoner's Dilemma, Stag Hunt, Chicken game, Battle of the Sexes and the Coordination game, as proposed by Robinson \& Goforth (2005); and (iii) Section 4 brings the final considerations and remarks.

\section{RESEARCH METHODOLOGY}

This paper has the goal to assess and analyze the relevant publications of game theory practical applications in the oil and gas industry. The search for these state-of-art publications was performed in four research databases: (i) Web of Science; (ii) Scopus; (iii) Scielo; and (iv) IEEExplore. The search strings used were "game theory applications in oil and gas", "game theory oil and gas", "game theory oil" and "game theory gas". This search aimed to find the most relevant and significant game theory applications or methodologies applied in the oil and gas industry. Other procedures applied to this search were the following: (i) filtering device to select only the papers published in the last 10 years; (ii) an advanced search mechanism was applied to look for the terms of the search string only in the title, abstract and keywords; and (iii) the article types were defined as only research articles. Journals impact factor, number of citations, and other metrics were not taken into account.

After the initial identification in the databases, one of the present authors was responsible for pre-selection of the most relevant papers by evaluating their titles, abstract and keywords. The criteria followed can be summarized in three items: (i) realistic examples and real-world situa- 
tions with an adequate structure in order to promote debates and generate discussions; (ii) game theory applications with more simplified and standardized payoff structures rather than studies with a more theoretical approach, or situations with more complex payoff structures; and (iii) relevant and significant dilemmas faced by the agents involved. These criteria were defined to guide for more practical applications that can significantly aid in the decision-making processes of the agents involved in the oil and gas industry. This stage concluded by pre-selecting 27 papers.

The selection stage was characterized as a full-text assessment of the 27 pre-selected papers according to the main criteria identified previously. This assessment was performed by the two authors of this paper. Following the above mentioned steps, six papers were excluded because they were outside the scope of the oil and gas industry, being more associated with subjects related to energy and electricity markets, such as network and distribution, retail prices, and energy demand analysis. Two other papers were removed because they were characterized as non-symmetric 2 x 2 strategic games, where players have different possible strategies and distinct payoff structures. Therefore, 19 papers were selected and grouped into two categories: (i) ten papers with pertinent information and discussion without a more formal or structured social and economic interaction among the agents involved; and (ii) nine papers which had a more standardized and organized structured form of a 2 × 2 strategic game. The latter group was assessed and analyzed according to the NPT proposed by Robinson \& Goforth (2005) and their payoff structures associated with one of the topologies of a $2 \times 2$ strategic game, such as the Prisoner's Dilemma, Battle of the Sexes, Stag Hunt, and others.

\section{RESULTS AND DISCUSSION}

The first group contributed to the overall study of potential scenarios and possible analysis of the oil and gas industry, bringing relevant contributions from game theory applications. However, they applied a distinct framework from the topologies of the 2 × 2 strategic games, making the analysis more difficult through the classification proposed by Robinson \& Goforth (2005). The 10 papers selected for this first group are the following: (i) Chang et al. (2014) proposed a new model for oil supply forecasting analyzing the OPEC and non-OPEC oil producers; (ii) Popescu \& Hurduzeu (2015) simulated various supply challenges and price scenarios for Europe; (iii) Li et al. (2013) analyzed the possibility of a more free market between China and Russia; (iv) Abada et al. (2012) studied natural gas long-term contracts in Europe; (v) Castillo \& Dorao (2012) proposed an algorithm to find the consensus output using cost functions; (vi) Castillo \& Dorao (2013) proposed a methodology for a decision-making problem of the design of a gas treatment facility; (vii) Willigers et al. (2009) evaluated a single production infrastructure for a oil and gas joint development project; (viii) Willigers \& Hausken (2013) studied the consequences of the United Kingdom (UK) tax adjustments in 2011; (ix) Yang et al. (2013) developed an environmental decision-making problem of an offshore oil and gas project; and (x) Cheung \& Zhuang (2012) proposed a framework to assess a safety regulatory game between governments and oil companies. 
The second group of papers were assessed and analyzed in the following sections according to the topologies of the 2 × 2 strategic games classification proposed by Robinson \& Goforth (2005). Robinson \& Goforth (2005) argued that the most relevant 2 x 2 strategic games are the following: (i) Prisoner's Dilemma, a Nash equilibrium that coincides with the Maxi-min solution, but this solution is not the highest payoff for the players; (ii) Stag Hunt, two Nash equilibria, one with bigger payoffs than the other, and the smaller coinciding with the Maxi-min solution; (iii) Chicken game, two reciprocal Nash equilibria and neither of them corresponding to the Maxi-min solution; (iv) two Battle of the Sexes games, both containing two reciprocal Nash equilibria and the first coinciding with the Maxi-min solution; and (v) two Coordination games, both containing two Nash equilibria but always only one solution with the highest possible payoffs for both players.

\subsection{Prisoner's Dilemma}

Decanio \& Fremstad (2013), Kelly (2003) and Robinson \& Goforth (2005) mentioned that Prisoner's Dilemma was the most frequent game theory application. This classical dilemma arises from a hypothetical situation in which two suspects are arrested, and offered to confess to the crime and testify against the other suspect or to refuse to confess. If both suspects do not confess, both will be arrested with a smaller sentence for minor crimes. If only one of the prisoners confesses, this one will receive a reduced penalty for collaboration with the police while the other prisoner, who does not confess, will receive the full sentence. If both prisoners confess, both will be penalized with an intermediate sentence due to collaboration (Osborne \& Rubinstein, 1994; Fiani, 2015). Osborne \& Rubinstein (1994) synthesized that in every Prisoner's Dilemma structure there is a tendency towards coordination among the players, where the Nash equilibrium is identified as both players confessing to the crime. On the other hand, there is also a strong incentive to take a free-riding strategy, aiming to obtain the highest payoff as possible. If any player chooses to deviate from this equilibrium it will lead this situation to an indefinite game in which repetition is allowed (Kelly, 2003).

According to Willigers et al. (2009) and Bratvold \& Koch (2011), the oil producers' dilemma is an example of the Prisoner's Dilemma practical application in the oil and gas industry. This game consists of two generic oil-producing countries (A and B) with the same goal of maximizing their oil revenues by deciding how much oil to produce as their strategies. For this practical application, it was assumed that each of the two countries could choose from two options: (i) low production (10 barrels of oil); and (ii) high production (20 barrels of oil). Each player decides to adopt the strategy that they believe will maximize their own oil revenues. The game assumes cardinal information using the oil price as a function of the total oil produced by the two countries (A and B), where there is a clear inverse relationship between oil output production and its price (Willigers et al., 2009). Table 2 synthesizes the payoffs for both countries.

The outcomes demonstrated that the oil producers' dilemma is a practical application of the Prisoner's Dilemma. The Nash equilibrium and Maxi-min solution are clearly identified as both players choosing the strategy of high production, even when both players choosing the strategy 
Table 2 - Oil producers' dilemma.

Source: Willigers et al. (2009) and Bratvold \& Koch (2011).

\begin{tabular}{c|c|c}
\hline \multirow{2}{*}{ Country A } & \multicolumn{2}{|c}{ Country B } \\
\cline { 2 - 3 } & Low Production & High Production \\
\hline Low Production & $\$ 1400 ; \$ 1400$ & $\$ 750 ; \$ 1500$ \\
\hline High Production & $\$ 1500 ; \$ 750$ & $\$ 800 ; \$ 800$ \\
\hline
\end{tabular}

of low production generated higher payoffs. The main issue faced in this game is that there is an incentive for both agents to break the deal and behave as a free-riding player, aiming to achieve the highest payoff as possible. Consequently, it is unlikely to expect that both countries will always limit their production to a low-level range without an additional contractual or enforcement process (Bratvold \& Koch, 2011). This break off will occur if one player considers the incentives for deviating, which includes their expected gain being higher than the coordinated solution (Kelly, 2003).

Schitka (2014) proposed a realistic non-cooperative game for the joint development or unitization of a reservoir involving neighboring landowners, simulating a practical application according to the regulations of US and Canada. This game follows the logical structure of the Prisoner's Dilemma, where two landowners have oil and gas resources in their bordering properties. Both landowners can choose between two different strategies: (i) joint development, cooperation or unitization in order to develop together these oil and gas resources; and (ii) drill solo, each landowner chooses to develop these resources by themself aiming to extract more, and faster, than their neighbor. Schitka (2014) mentioned that a unitization strategy could potentially allow a more efficient exploration of the reservoir and more oil and gas to be extracted. However, each landowner also has the opportunity to drill as many wells as possible, being able to extract more, and faster, oil and gas from these wells. Table 3 summarizes the payoffs identified for this hypothetical game.

Table 3 - Reservoir joint development or unitization negotiations.

Source: Schitka (2014).

\begin{tabular}{c|c|c}
\hline \multirow{2}{*}{ Player 1 } & \multicolumn{2}{|c}{ Player 2 } \\
\cline { 2 - 3 } & Joint development & Drill solo \\
\hline Joint development & $125 ; 125$ & $50 ; 150$ \\
\hline Drill solo & $150 ; 50$ & $100 ; 100$ \\
\hline
\end{tabular}

In this non-cooperative game, the only Nash equilibrium and Maxi-min solution is identified as both players assuming the strategy of drilling solo. However, each player has a strong tendency to explore their common oil and gas resources based on the chance of obtaining more oil and gas than their neighbor. It is possible to observe that the highest payoffs are in the option of drilling 
solo, by assuming a free-riding strategy. Nevertheless, this choice results in an inefficient development of the reservoir as a whole because of quick pressure depletion and gas cap releasing, which characterizes the drop of reservoir's driving force that allows the resources to be extracted (Schitka, 2014).

Finally, Esmaeili et al. (2015) used the same logical structure of the Prisoner's Dilemma, but here with ordinal information, to understand and model the conflict between Iran and Qatar in the development of two common oil fields (South Pars and North Dome) located within their borders. This game assumed that Iran and Qatar have two possible strategies: (i) low extraction rate (LER); and (ii) high extraction rate (HER). At first, both countries may presume that the more they extract, the more they gain. On the other hand, the oil reserves would quickly drop and the extracting costs would increase if the high extraction strategy was applied by both countries. However, if both countries chose the strategy of a low extraction rate (LER), the reservoirs' levels would slowly decrease, and the countries would enjoy long-term profits. In other words, it seems that a cooperative strategy is indicated for both countries. Nevertheless, there is still an incentive to perform a free-riding strategy by choosing a high extraction rate (HER) as long as the other player prefers a low extraction rate (LER) option, in order to achieve the highest possible payoff, which can be visualized in Table 4 .

Table 4 - Iran-Qatar conflict over the fields of South Pars and North Dome.

Source: Esmaeili et al. (2015).

\begin{tabular}{c|c|c}
\hline \multirow{2}{*}{ Iran } & \multicolumn{2}{|c}{ Qatar } \\
\cline { 2 - 3 } & $\begin{array}{c}\text { Low Extraction Rate } \\
(\text { LER })\end{array}$ & $\begin{array}{c}\text { High Extraction Rate } \\
\text { (HER) }\end{array}$ \\
\hline Low Extraction Rate (LER) & $2 ; 2$ & $0 ; 3$ \\
\hline High Extraction Rate (HER) & $3 ; 0$ & $1 ; 1$ \\
\hline
\end{tabular}

In this particular real-world application, Qatar enjoys the benefits of a higher extraction rate (HER) in a free-riding strategy. In contrast, Iran is making the least profit from these common oil and gas resources in the current situation by adopting the strategy of low extraction rate (LER) (Esmaeili et al., 2015). Nonetheless, the current situation can change as soon as Iran implements a different strategy in order to achieve a higher extraction rate. In any Prisoner's Dilemma game, when each player searches for their highest possible outcome this will potentially lead to a situation that is not the best payoff for both players (Fiani, 2015).

\subsection{Stag Hunt game}

Robinson \& Goforth (2005) described this situation as two hunters agreeing to hunt a stag or individually hunt a hare. Hunting stags is a quite challenging task where if both hunters decide to hunt a stag alone, their chance of success will be minimal. In other words, hunting a stag is the most beneficial for both players but requires a lot of trust and commitment among them. In 
other words, if one of the players makes the decision to hunt a hare, the one who has remained faithful to their initial commitment will be harmed and will not be able to hunt a stag (Fiani, 2015). Decanio \& Fremstad (2013) added that the best solution for both players is only reached when they choose the same strategy and keep their original arrangement.

Esmaeili et al. (2015) proposed a game based on a real-world conflict between Iran and Iraq for the exploration and production of their shared oil and gas resources, which includes 20 common oil and gas fields located along their border. Both countries have two possible strategies: (i) maximum extraction rate (MER), the highest oil and gas production rate in the shortest time; and (ii) low extraction rate (LER), the lowest oil and gas production rate according to the reservoir conditions. The logical structure behind the exploration of these shared resources is that if both countries cooperate and explore these fields with a reasonable extraction rate, less than the maximum rate, the long-term benefits of proper maintenance will exceed the revenue losses from extracting less than the maximum (Esmaeili et al., 2015). Fiani (2015) argued that the best outcome for both players in a classical Stag Hunt game strongly depends on their commitment to their initial agreement (Table 5).

Table 5 - Iran-Iraq conflict over shared oil and gas resources located in their borders.

Source: Esmaeili et al. (2015).

\begin{tabular}{c|c|c}
\hline \multirow{2}{*}{ Iran } & \multicolumn{2}{|c}{ Iraq } \\
\cline { 2 - 3 } & $\begin{array}{c}\text { Low Extraction Rate } \\
(\text { LER) }\end{array}$ & $\begin{array}{c}\text { Maximum Extraction Rate } \\
(\text { MER) }\end{array}$ \\
\hline Low Extraction Rate (LER) & $3 ; 3$ & $0 ; 2$ \\
\hline Maximum Extraction Rate (MER) & $2 ; 0$ & $1 ; 1$ \\
\hline
\end{tabular}

The highest outcome for both countries is a Nash equilibrium that comprehends the strategy of a low extraction rate (LER). There is also another Nash equilibrium when both players choose a maximum extraction rate (MER). In a classical Stag Hunt game, the players' choices are deeply affected by mutual trust and past negotiations, which can be tough due to a history of wars, conflicts and invasions between Iran and Iraq (Esmaeili et al., 2015). The current situation states that the oil extraction rate of Iraq is more than double than the rate of Iran. It means that Iraq assumed a free-riding strategy and achieved better outcomes than Iran in this situation. However, it is expected that in the near future both countries reach an agreement to develop their common oil and gas resources, which should result in long-term benefits for both (Esmaeili et al., 2015).

Inaba $(2015 ; 2016)$ proposed a realistic application of a Stag Hunt game based on historical examples of business cooperation in Japanese oil and petrochemical plants, especially in the matters of energy-saving, actions on environmental problems, security of global competitiveness, and restructuring of production systems. This game is composed of two oil and petrochemical companies (A and B) that are evaluating the possibilities of cooperating and executing joint operations. Hence, both companies can assume two possible strategies: (i) continue with their 
independent business; and (ii) perform business cooperation. The main goal of this game is to evaluate the payoffs for both companies by choosing collaborative cooperation or by keep undertaking independent business, following the logical structure of a classical Stag Hunt game. Table 6 shows the players' payoffs for this practical application.

Table 6 - Cooperation dilemma faced by Japanese oil and petrochemical plants.

Source: Inaba $(2015 ; 2016)$.

\begin{tabular}{c|c|c}
\hline \multirow{2}{*}{ Company A } & \multicolumn{2}{|c}{ Company B } \\
\cline { 2 - 3 } & Independent business & Business cooperation \\
\hline Independent business & $3 ; 2$ & $3 ; 0$ \\
\hline Business cooperation & $0 ; 2$ & $7 ; 4$ \\
\hline
\end{tabular}

It is possible to see that the business coordination strategy is that with the highest payoffs, even with different values for each player, as is the Nash equilibrium of this game. In other words, both companies can achieve higher outcomes when they coordinate with each other and execute joint operations. Both companies will receive intermediate gains when their strategy is to keep undertaking independent business, which is another Nash equilibrium. However, if company A or B decides to break off this collaborative relationship and continue undertaking independent business, the players' outcomes will be strongly affected (Inaba, 2016), especially for the player who kept the initial agreement of business cooperation.

\subsection{Chicken game}

The Chicken game approach comes from an old James Dean movie, called "Rebel without a cause", where two teenage boys drive cars at high-speed toward a cliff edge to see who is the first one to brake and chicken out (Binmore, 2007). Fiani (2015) defines this classical game as a dangerous form of destructive competition, where two teenagers drive at high-speed towards each other to see who will deviate first. In a Chicken game, the coordinated solutions are usually the ones with the least-favored outcomes, where both players have high incentives to assume a different strategy from the other player in a free-riding strategy (Decanio \& Fremstad, 2013).

Esmaeili et al. (2015) proposed a practical application of the Chicken game to analyze the conflict between Iran and Iraq in a region close to the Fakka oil field. This particular region has several historical border controversy issues. In 2009, an incident occurred when Iranian troops invaded this region for some period, and later left the territory due to a possible military reaction from Iraq. Therefore, in this situation, Iran and Iraq can assume two strategies: (i) (C), abandoning the region and not exploring the oil and gas resources; and (ii) (D), staying in the region and benefiting from the oil and exploration. Table 7 shows the payoffs for each player in this realworld situation. 
Table 7 - Iran-Iraq conflict over the Fakka oil field region.

Source: Esmaeili et al. (2015).

\begin{tabular}{c|c|c}
\hline \multirow{2}{*}{ Iran } & \multicolumn{2}{|c}{ Iraq } \\
\cline { 2 - 3 } & $(\mathrm{C})$ & $(\mathrm{D})$ \\
\hline (C) & $3 ; 3$ & $2 ; 4$ \\
\hline (D) & $4 ; 2$ & $1 ; 1$ \\
\hline
\end{tabular}

The payoff outcomes indicated two Nash equilibria when players assume different strategic options, such as $(\mathrm{C}, \mathrm{D})$ or $(\mathrm{D}, \mathrm{C})$, where one of the countries would explore and produce the oil field obtaining the greatest benefits, while the other player would leave the area empty-handed (Esmaeili et al., 2015). The other possible outcomes of this conflict happen when both players select the same strategy (C), resulting in both countries leaving the field unexploited for the future. If both countries chose (D), a catastrophic outcome would happen, which could lead to military action, being the lowest payoff for both countries considering the high political risks (Esmaeili et al., 2015).

\subsection{Battle of Sexes}

Luce \& Raiffa (1957) described this game as an evaluation of two entertainment events for a couple, where the husband would rather go to a fight event and the wife to a ballet. Each player prefers a different option, however, it is more important for them to go together than each one going individually to their preferred event. This game represents a situation in which players always have better payoffs when their decisions are coordinated, even with distinct preferences about an action to be performed (Fiani, 2015). This classic game model is the same for situations where players wish to coordinate their behaviors, but have conflicting interests (Osborne \& Rubinstein, 1994). Robinson \& Goforth (2005) concluded that Battle of Sexes games allow mutual gain for both players, but distributionally different Nash equilibria.

Schitka (2014) proposed a realistic application of an oil and gas reservoir allocation based on a classical Battle of the Sexes game. Assuming that both players agreed to make a joint reservoir development or unitization arrangement, another issue would show up. This issue is characterized as the allocation formula, which will determine what portion of the produced oil and gas each landowner will receive. This allocation formula can create several potential conflicts during the reservoir unitization negotiations to determine how the resources will be explored, and how the earnings will be distributed to the landowners. The main assumption of this game is that both players are in a more advantageous position by agreeing on an appropriated allocation formula, than when each one pursues their individual interests (Schitka, 2014), as demonstrated by the players payoffs in Table 8. 
Table 8 - Allocation formula during joint development or unitization negotiations.

Source: Schitka (2014).

\begin{tabular}{c|c|c}
\hline \multirow{2}{*}{ Player 1 } & \multicolumn{2}{|c}{ Player 2 } \\
\cline { 2 - 3 } & Unit Plan 1 & Unit Plan 2 \\
\hline Unit Plan 1 & $50 ; 40$ & $-100 ;-100$ \\
\hline Unit Plan 2 & $-100 ;-100$ & $40 ; 50$ \\
\hline
\end{tabular}

The payoff outcomes show that the strategy of "Unit Plan 1" is more desirable to player 1, while the strategy of "Unit Plan 2" is more appropriate to player 2. However, only the coordination of both players in the same strategy will prevent them from having negative payoffs. In other words, both coordinated strategies are identified as Nash equilibria, indicating a more efficient development of the common reservoirs, allowing more oil and gas to be extracted than otherwise would have been possible by each player by themself. Schitka (2014) mentioned that unitization agreements or joint developments were not a trivial negotiation because of the potential conflicts of interest between both landowners. Hence, several techniques should be used to promote coordinated negotiations, such as: (i) tit-for-tat strategy: one party gives up something in the negotiation in exchange for the other party making a similar concession; (ii) promotion of coalition solutions: the ability to formulate proposals that may simultaneously advance the interests of everyone involved in the negotiation; and (iii) cramdown options: negotiation possibilities that allow an agreement in a multilateral conciliation and by meeting some threshold (Schitka, 2014).

Wood et al. (2016) proposed to evaluate the world oil market during the 1960s and 1970s based on an adaptation of the classical Battle of the Sexes game by analyzing two players, namely: (i) the OPEC countries; and (ii) the Seven Sisters. The OPEC countries are characterized as a set of countries with abundant oil reserves joined together in an association to defend their specific interests. On the other side, the Seven Sisters represented seven major oil firms, namely Shell, BP, Gulf, Chevron, Texaco, Exxon and Mobil, with significant dominant force in global petroleum markets, especially in the decades following World War II (Wood et al., 2016). During the 1960s and 1970s, about three-quarters of the proven oil and gas reserves in the world were located in OPEC countries (Mommer, 1999). Significant changes in the oil and gas industry were identified during this period (1960s and 1970s), where OPEC countries and major oil companies were fighting to get overall market control and not caring so much about price or revenue (Johnston, 2008).

According to Wood et al. (2016), the OPEC countries and the Seven Sisters were a heterogeneous population of agents struggling for control over the global petroleum market. The proposed game assumed that the OPEC countries could have two strategies: (i) full production (active rule), supplying the world with abundant oil at low prices; and (ii) prorate (passive rule), cutting the oil production to a specific fraction of the available output. On the other hand, the Seven Sisters 
strategies were identified as the following: (i) dominate (active rule), struggling to set oil prices and production levels; and (ii) acquiesce (passive rule), letting the OPEC countries control the prices and the production levels while focusing on other aspects of the oil industry, such as logistics and end-use sales. Table 9 shows the payoffs associated with the possible strategies of both players.

Table 9 - Market dominance of OPEC countries and Seven Sisters in the 1960s and 1970s.

Source: Wood et al. (2016).

\begin{tabular}{c|c|c}
\hline \multirow{2}{*}{ OPEC Countries } & \multicolumn{2}{|c}{ Seven Sisters } \\
\cline { 2 - 3 } & Dominate & Acquiesce \\
\hline Full production & $\mathrm{A} ; \mathrm{B}$ & $\mathrm{C} ; \mathrm{D}$ \\
\hline Prorate & $\mathrm{D} ; \mathrm{C}$ & $\mathrm{B} ; \mathrm{A}$ \\
\hline
\end{tabular}

Wood et al. (2016) assumed that the payoffs followed the sequential logic of "B" > "A" > "C" $>$ "D". The Nash equilibria would only be achieved when both players agreed to coordinate and choose the same strategy. It is possible to observe that " $\mathrm{B}$ " was the payoff earned by the agent who controlled the market, while "A" was the payoff for coordinating with a dominant opponent. These payoff outcomes indicated that this was a leader-follower model, which offered the greatest payoffs for both players when they cooperated, and the leader earned a slightly higher payoff than the follower. The payoffs "C" and "D" were associated with coordination failures with the lowest possible gains for both players. The logical structure of this practical application is very similar to a classical game of Battle of the Sexes, where only the coordination of the players' actions would result in the best solutions, even with initial conflicting preferences (Wood et al., 2016).

\subsection{Coordination game}

Robinson \& Goforth (2005) indicated that Coordination games differ from the Battle of the Sexes and Stag Hunt games in having only one outcome, a Nash equilibrium, always preferred by all players involved. Rapoport \& Guyer (1978) classified all Coordination games identified by Robinson \& Goforth (2005) as "no-conflict" games because the strategy choice of the players does not involve a serious problem for them, due to their similar preferences represented by their payoff outcomes.

Amorelli \& Carpio (2016) evaluated the possibility of cooperation among oil and gas companies in unitization processes in Brazil using a Coordination game. By reviewing previous approved unitization contracts in Brazil, the authors have noted that the Brazilian National Oil Company (Petrobras) was always one of the players involved (Company 1) in these negotiations, indicating its predominance in the country's oil and gas market. Consequently, the game assumes that Petrobras was regularly the leading agent with strong interests in these negotiations with several other oil and gas private companies operating in Brazil (Company 2). The game is structured by 
two possible strategies: (i) cooperate (C); and (ii) not cooperate (NC). Table 10 describes the payoff matrix according to the players' strategy.

Table 10 - Practical application of unitization agreements in Brazil.

Source: Amorelli \& Carpio (2016).

\begin{tabular}{c|c|c}
\hline \multirow{2}{*}{ Company 1 } & \multicolumn{2}{|c}{ Company 2 } \\
\cline { 2 - 3 } & Cooperate $(\mathrm{C})$ & Not cooperate $(\mathrm{NC})$ \\
\hline Cooperate $(\mathrm{C})$ & $\pi_{C 1} ; \pi_{C 2}$ & $\pi_{C 1}^{\prime} ; \pi_{N C 2}$ \\
\hline Not cooperate $(\mathrm{NC})$ & $\pi_{N C 1} ; \pi_{C 2}^{\prime}$ & $\pi_{p 1} ; \pi_{p 2}$ \\
\hline
\end{tabular}

Amorelli \& Carpio (2016) argued that assuming unitization negotiations between Petrobras and other players happens in infinitely repeated games, as long as both companies have sufficient capital to cover the setup costs, and the gains in cooperation strategies $\left(\pi_{C i}\right)$ are greater than those in non-cooperation strategies $\left(\pi_{P i}\right)$. In the case of the leading player (Petrobras) deciding to hold a non-cooperative strategy $\left(\pi_{N C i}\right)$, assuming that the other player wants to cooperate $\left(\pi_{C i}^{\prime}\right)$, it will result in the least optimal outcome due to a potential crisis of confidence by the other oil and gas companies for future unitization negotiations, as well as interfering negatively in the willingness of these companies to invest in Brazil. On the other hand, when the other oil and gas companies assume a non-cooperation strategy $\left(\pi_{N C i}\right)$ and Petrobras is willing to cooperate $\left(\pi_{C i}^{\prime}\right)$, the other companies will bargain for better conditions in negotiations with Petrobras or will sell their rights to others and leave this region (Amorelli \& Carpio, 2016). In summary, the payoffs of Petrobras (Company 1) are estimated as the following logical sequence: " $\pi_{C 1}$ " > " $\pi_{C 1}^{\prime} ">$ " $\pi_{N C 1} ">$ " $\pi_{P 1}$ ". The other private oil and gas company (Company 2 ) has a slightly different logical payoff sequence, identified as: " $\pi_{C 2}$ " $>$ " $\pi_{N C 2}$ " $>$ " $\pi_{C 2}^{\prime}$ " $>$ " $\pi_{P 2}$ ". It is possible to visualize that the Nash equilibrium, and the best strategy for both players happened when both companies decided to cooperate. In the same way, the worst strategy was identified when both players did not cooperate. This interact situation leads to a pure common-interest game, where the players payoffs represent a symmetrical diagonal in which every payoff-improving strategy change of one player increases the payoffs for the other player (Robinson \& Goforth, 2005). Amorelli \& Carpio (2016) concluded that Petrobras has an important predominance in the Brazilian oil and gas market, providing an additional advantage in unitization negotiations. However, non-cooperation strategies could result in a potential loss of business partners and financial strength for new ventures of Petrobras in the future.

Fattouh et al. (2016) used a framework based on a Coordination game to analyze the Saudi Arabian strategic choices in order to achieve its objectives of maintaining market share and maximizing revenue. There is a huge trade-off identified between these two objectives, depending on market conditions and the behavior of other major oil producers. In other words, the strategic choices of other OPEC countries could strongly impact in Saudi Arabia's specific objectives of market share and revenue. Therefore, the players involved are: (i) Saudi Arabia; and (ii) other 
OPEC countries. The game is structured by assuming two strategies: (i) cutting oil output; and (ii) does not change oil output. Fattouh et al. (2016) mentioned that the advent of US shale reservoirs changed the market conditions, making it more difficult for Saudi Arabia and other OPEC countries to choose their oil output strategy. These market conditions were evaluated in two different strategic games by assuming an elastic and an inelastic US shale oil supply. If the US shale oil supply is elastic, an oil output cut by Saudi Arabia and other OPEC countries will not likely influence the oil price because it would be replaced by the oil produced from US shale. On the other hand, by assuming that the US shale is inelastic, an oil output cut by Saudi Arabia and other OPEC countries would influence the oil price. Table 11 demonstrates this oil output dilemma, and the payoffs associated assuming an elastic US shale oil supply.

Table 11 - Saudi Arabia and OPEC countries in an elastic US supply.

Source: Fattouh et al. (2016).

\begin{tabular}{c|c|c}
\hline \multicolumn{3}{c}{ Elastic US Supply (Game 1) } \\
\hline \multirow{2}{*}{ Saudi Arabia } & \multicolumn{2}{|c}{ Other OPEC Countries } \\
\cline { 2 - 3 } & Cut output & Does not change output \\
\hline Cut output & $-\mathrm{C} ;-\mathrm{C}$ & $-\mathrm{A} ; \mathrm{O}$ \\
\hline Does not change output & $\mathrm{O} ;-\mathrm{A}$ & $\mathrm{O} ; \mathrm{O}$ \\
\hline
\end{tabular}

Fattouh et al. (2016) argued that the payoffs represent the gains or losses in comparison to Saudi Arabia and other OPEC countries' strategy of inaction, in which there is no change in their oil output. The outcomes can be summarized in: (i) payoff "-C", lowest loss due to an oil output cut in the presence of a falling market share; and (ii) payoff "-A", highest level of loss when both players drop their market share and revenue. The Nash equilibrium and the highest payoff are identified when both players do not change their oil output. This game has a topology of coordination game number 331, where both players agreed that the best solution for them is to coordinate their actions, because any change can potentially decrease their payoffs (Robinson \& Goforth, 2005). The results of this game indicated that under the uncertainty of US shale elasticity, it is safer for Saudi Arabia to assume that the US shale oil supply is elastic and does not cut its oil output. However, after learning more about this new source of oil supply to one of the biggest oil importers (USA), Saudi Arabia's policy should adapt accordingly (Fattouh et al., 2016).

The second game modeled by Fattouh et al. (2016) has the same players and possible strategic options but distinct market conditions by assuming that the US shale oil supply is inelastic. In this particular case, both players (Saudi Arabia and other OPEC countries) faced the dilemma of cutting or not cutting their outputs, where these cuts in the oil supply would potentially influence the oil prices and impact both players' total revenues. The main dilemma is to assess whether the revenue lost as a result of lower production outweighs the gains in revenues from higher prices. Table 12 brings the players' payoffs according to an inelastic US shale oil output condition. 
Table 12 - Saudi Arabia and OPEC countries in an inelastic US supply.

Source: Fattouh et al. (2016).

\begin{tabular}{c|c|c}
\hline \multicolumn{3}{c}{ Inelastic US Supply (Game 2) } \\
\hline \multirow{2}{*}{ Saudi Arabia } & \multicolumn{2}{|c}{ Other OPEC Countries } \\
\cline { 2 - 3 } & Cut output & Does not change output \\
\hline Cut output & $\mathrm{A} ; \mathrm{A}$ & $\mathrm{C} ; \mathrm{B}$ \\
\hline Does not change output & $\mathrm{B} ; \mathrm{C}$ & $\mathrm{O} ; \mathrm{O}$ \\
\hline
\end{tabular}

The payoffs visualized in Table 12 can be summarized as: (i) payoff "A", highest gain obtained when both players unanimously cut their output without any possibility of substitution; (ii) payoff "B", moderate gain of one player due to the oil output cut of the other player; and (iii) payoff "C", lowest gain when one player cut its oil output, and the other does not change its oil output. The analysis of this strategic interaction leads to a harmony game (game number 366), where both players have Nash equilibrium and can achieve their best payoffs simultaneously under the same strategy of cutting output (Robinson \& Goforth, 2005). Fattouh et al. (2016) concluded that Saudi Arabia and other OPEC countries would have better benefits under the assumption of an inelastic US oil supply and that there is a single optimal coordinated option.

\section{CONCLUSIONS REMARKS}

Game theory is characterized as a set of tools and techniques to understand the interactions among distinct agents and how these interactions can affect their payoff expectations. A very common game theoretical framework of modeling social and economic phenomenon is the 2 x 2 strategic game, including Prisoner's Dilemma, Stag Hunt, Chicken game, Battle of the Sexes and the Coordination game. In markets or industries such as the oil and gas, these games demonstrated to be useful for modeling and solving potential conflicts in the decision-making processes. Therefore, this paper contributes to the literature by evaluating realistic and realworld situations faced by the oil and gas industry that used a game theory approach for aiding in the understanding of the strategic interactions and the estimation of the agents' payoffs. It is important to highlight that several important agents of the oil and gas industry, such as oil producing and consuming countries, governments, and companies, were assessed and evaluated through some of the 2 × 2 strategic games analyzed.

The topologies of $2 \times 2$ strategic games have a simplified framework of modeling social and economic phenomenon with only 2 players and 2 possible actions. These topologies were applied to capture the essence of the strategic interaction of realistic and real-world applications of the oil and gas industry, for instance companies' partnerships and joint ventures, reservoir optimization and unitization agreements, cooperation strategies, and relationship between producing and consuming countries. The main goal was to aid in the decision-making processes by investigating the core logic behind the interests of the agents involved, aiming to understand their 
motivations, predict the consequences of their strategic interactions and, consequently, analyze their payoff preferences. The main results of this paper indicated that these agents can apply a wide range of strategies, such as free-riding strategies by pursuing only their individual interests, commitment or breakup of their initial agreement, the possibility of coordinated actions, cooperative strategies, and others. Therefore, the understanding and analysis of the main logic behind the topologies of 2 x 2 strategic games, such as Prisoner's Dilemma, Stag Hunt, and Battle of the Sexes, can aid in the improvement of decision-making processes of particular issues faced by the agents involved in the oil and gas industry.

In future works, a deeper analysis of the oil and gas applications without a more formal and standard form is recommended. These kinds of applications usually aim to model and solve particular issues faced by the oil and gas industry, which were not in the main scope of this paper. Other potential sources of future research are that several conflicts of interests among the players involved in the oil and gas industry were still not properly addressed by formal methodologies or techniques. The formalization of these potential issues can provide a better understanding and evaluation of real-world situations, consequently improving the decision-making processes.

\section{ACKNOWLEDGEMENTS}

CAPES for the Master's Scholarship in the DS-CAPES Program and two anonymous referees for their helpful comments and suggestions. We also thank John Carpenter (Ribeirão Preto, SP, Brazil) for the English language revision.

\section{REFERENCES}

[1] Abada I, Gabriel S, Briat V \& Massol O. 2012. A generalized Nash-Cournot model for the northwestern European natural gas markets with a fuel substitution demand function: The GaMMES model. Networks and Spatial Economics, 13(1): 1-42.

[2] Amorelli DC \& CARPio LGT. 2016. Unitization of oil and gas fields in Brazil. Energy Sources, Part B: Economics, Planning, and Policy, 11(9): 793-800.

[3] Arsenyan J, Buyukozkan G \& Feyzioglu O. 2015. Modeling collaboration formation with a game theory approach. Expert Systems with Applications, 42(4): 2073-2085.

[4] Binmore K. 2007. Playing for Real: A text on Game Theory. Oxford University Press, New York, NY.

[5] BRams SJ. 1994. Theory of Moves. Cambridge University Press, Cambridge, MA.

[6] BRatvold RB \& Koch F. 2011. Game Theory in the Oil and Gas Industry. SPE The Way Ahead, 7(1): 18-20.

[7] Castillo L \& Dorao CA. 2012. Consensual decision-making model based on game theory for LNG processes. Energy Conversion and Management, 64(1): 387-396.

[8] Castillo L \& Dorao CA. 2013. Decision-making in the oil and gas projects based on game theory: Conceptual process design. Energy Conversion and Management Journal, 66(1): 48-55. 
[9] Chang Y, Yi J, Yan W, Yang X, Zhang S, GaO Y \& Wang X. 2014. Oil supply between OPEC and non-OPEC based on game theory. International Journal of Systems Science, 45(10): 2127-2132.

[10] Cheung M \& Zhuang J. 2012. Regulation Games Between Government and Competing Companies: Oil Spills and Other Disasters. Decision Analysis, 9(2): 156-164.

[11] Decanio SJ \& Fremstad A. 2013. Game theory and climate diplomacy. Ecological Economics, 85(2013): 177-187.

[12] Esmaeili M, BAhrini A \& ShayAnrad S. 2015. Using game theory approach to interpret stable policies for Iran's oil and gas common resources conflicts with Iraq and Qatar. Journal of Industrial Engineering International, 11(4): 543-554.

[13] INABA K. 2015. The application of stag hunt game to business cooperation of industrial complexes in Japan. Proceeding of the $12^{\text {th }}$ International Conference on Innovation and Management, IEEE Conference on Computer Science, Wuhan, China, p. 1048-1051.

[14] INABA K. 2016. The common integration historical developed form of group operation of petrochemical complexes in Japan. Enerugih-shi Kenkyu [Research of Energy History], Kyusyu University, p. 89-108.

[15] Fiani R. 2015. Teoria dos jogos (Game Theory), Elsevier, $4^{\text {th }}$ edition, Rio de Janeiro, RJ, Brazil.

[16] Fattouh B, Poudineh R \& Sen A. 2016. The dynamics of the revenue maximization-market share trade-off: Saudi Arabia's oil policy in the 2014-15 price fall. Oxford Review of Economic Policy, 32(2): 223-240.

[17] Hamacher S \& Martins VF. 2015. Aplicações de Pesquisa Operacional na Indústria Internacional de Petróleo e Gás (Operational Research applications in the international oil and gas industry), Elsevier, 1st edition, Rio de Janeiro, RJ, Brazil.

[18] Hipel KW, Kilgour DM \& FAng L. 2011. The graph model for conflict resolution, John Wiley \& Sons, Inc., Wiley Encyclopedia of Operations Research and Management Science.

[19] Johnston D. 1994. International Petroleum Fiscal Systems and Production Sharing Contracts. Penn Well Books, Tulsa, OK.

[20] Johnston D. 2008. Changing Fiscal Landscape. Journal of World Energy Law and Business, 1(1): $31-54$.

[21] Kelly A. 2003. Decision Making using Game Theory: an introduction to managers. Cambridge University Press, Cambridge, UK.

[22] Li F, Li T \& Ding X. 2013. The Game Analysis and Measures of Sino-Russia Oil Project Cooperation. Applied Mechanics and Materials, 291-294(2013): 1255-1258.

[23] Lopes YG \& Almeida AT. 2013. A Multicriteria Decision model for selecting a portfolio of oil and gas exploration projects. Pesquisa Operacional, 33(3): 417-441.

[24] LuCE RD \& RAIfFA H. 1957. Games and Decisions. John Wiley and Sons, Inc. Harvard University. New York, NY.

[25] Mommer B. 1999. Oil Prices and Fiscal Regimes, WPM 24. Oxford Institute for Energy Studies, University of Oxford, UK.

[26] Nakhle C. 2008. Petroleum Taxation: Sharing the oil wealth. Routledge Studies in International Business and the World Economy, New York, NY. 
[27] NASH JF. 1951. Non-Cooperative Games. Annals of mathematics, Second Series, 54(2): 286-295.

[28] Oliveira F, Nunes PM, Blajberg R \& Hamacker S. 2016. A framework for crude oil scheduling in an integrated terminal-refinery system under supply uncertainty. European Journal of Operational Research, 252(2016): 635-645.

[29] Osborne MJ \& Rubinstein A. 1994. A Course in Game Theory. The MIT Press, Cambridge, MA.

[30] Popescu MF \& Hurduzeu G. 2015. Energy Challenges for Europe - Scenarios of the Importance of Natural Gas Prices from a Game. Journal of Game Theory, 4(2): 26-35.

[31] RAPOPORT A \& GUYer MJ. 1978. A Taxonomy of $2 \times 2$ Games. General Systems, XXIII: 125-136.

[32] RApoport A, Guyer MJ \& Gordon DD. 1976. The $2 \times 2$ Game. University of Michigan Press, Ann Arbour, MI.

[33] Robinson D \& Goforth D. 2005. The Topology of the $2 \times 2$ Games: A New Periodic Table. Routledge, New York, NY.

[34] SchitKa BB. 2014. Applying game theory to oil and gas unitization agreements: how to resolve mutually beneficial, yet competitive situations. The Journal of World Energy Law \& Business, 7(6): $572-581$.

[35] Seixas E. 2009. Redes estratégicas no contexto luso-brasileiro: estudo de caso na indústria do petróleo (Strategic networks in the Portuguese-Brazilian context: a case study in the oil industry). Master Thesis, Fundação Getúlio Vargas, Rio de Janeiro, RJ, Brazil.

[36] SouZA FC \& REGo LC. 2013. Collaborative dominance: when doing unto others as you would have them do unto you is reasonable. Pesquisa Operacional, 33(3): 467-476.

[37] Willigers BJA, Bratvold RB \& Hausken K. 2009. A game theoretic approach to conflicting and evolving stakeholder preferences in the E\&P industry. SPE Economics and Management, No. 1, SPE 124178, pp. 19-26.

[38] Willigers BJA \& HAUSKen K. 2013. The strategic interaction between the government and international oil companies in the UK: An example of a country with dwindling hydrocarbon reserves. Energy Policy, 57(2013): 276-286.

[39] Wood AD, Mason CF \& FInnoff D. 2016. OPEC, the Seven Sisters, and oil market dominance: An evolutionary game theory and agent-based modeling approach. Journal of Economic Behavior \& Organization, 132(2016): 66-78.

[40] Yang M, Khan FI, SAdiQ R \& Amyotte P. 2013. A rough set-based game theoretical approach for environmental decision-making: A case of offshore oil and gas operations. Process Safety and Environmental Protection Journal, 91(3): 172-182.

[41] ZHU Q \& SINGH G. 2016. The impacts of oil price volatility on strategic investment of oil companies in North America, Asia, and Europe. Pesquisa Operacional, 36(1): 1-21. 